Alimentary Tract

\title{
The who-when-why triangle of complementary and alternative medicine use among Portuguese IBD patients
}

Francisco Portela $^{\mathrm{a}, *}$, Camila C. Dias ${ }^{\mathrm{b}, \mathrm{c}}$, Paulo Caldeira ${ }^{\mathrm{d}}$, Marilia Cravo ${ }^{\mathrm{e}}$, João Deus ${ }^{\mathrm{f}}$, Raquel Gonçalves ${ }^{g}$, Paula Lago ${ }^{\mathrm{h}}$, Henrique Morna ${ }^{\mathrm{i}}$, Paula Peixe ${ }^{\mathrm{j}}$, Jaime Ramos ${ }^{\mathrm{k}}$, Helena Sousa $^{\mathrm{d}, \mathrm{l}}$, Lurdes Tavares ${ }^{\mathrm{m}}$, Helena Vasconcelos ${ }^{\mathrm{n}}$, Fernando Magro ${ }^{\mathrm{o}, \mathrm{p}, \mathrm{q}}$, Paula Ministro ${ }^{\mathrm{r}}$

a Serviço de Gastrenterologia, Centro Hospitalar Universitário de Coimbra, Coimbra, Portugal

b CIDES - Department of Health Information and Decision Sciences, Faculty of Medicine, University of Porto, Portugal

${ }^{\mathrm{c}}$ CINTESIS - Centre for Health Technology and Services Research, Porto, Portugal

d Gastroenterology Department, Centro Hospitalar do Algarve, Portugal

e Serviço de Gastrenterologia, Hospital Beatriz Ângelo, Loures, Portugal

f Serviço de Gastrenterologia, Hospital Fernandes da Fonseca, Amadora, Portugal

' Serviço de Gastrenterologia, Hospital de Braga, Braga, Portugal

${ }^{\mathrm{h}}$ Gastroenterology Department, Centro Hospitalar Porto-Hospital Santo António, Portugal

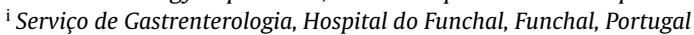

${ }^{j}$ Serviço de Gastrenterologia, Centro Hospitalar de Lisboa Ocidental, Lisboa, Portugal

k Serviço de Gastrenterologia, Hospital dos Capuchos, Lisboa, Portugal

${ }^{1}$ Biomedical Sciences and Medicine Department, University of Algarve, Portugal

m Serviço de Gastrenterologia, Hospital de Santa Maria, Lisboa, Portugal

n Serviço de Gastrenterologia, Hospital de Santo André, Leria, Portugal

${ }^{\circ}$ Gastroenterology Department, Centro Hospitalar São João, Porto, Portugal

p Department of Pharmacology and Therapeutics, Faculty of Medicine, University of Porto, Portugal

${ }^{q}$ MedInUP - Centre for Drug Discovery and Innovative Medicines, University of Porto, Portugal

${ }^{\mathrm{r}}$ Serviço Gastrenterologia, Centro Hospitalar de Tondela - Viseu, Viseu, Portugal

\section{A R T I C L E I N F O}

\section{Article history:}

Received 1 December 2016

Received in revised form

29 December 2016

Accepted 30 December 2016

Available online 6 January 2017

\section{Keywords:}

Complementary and alternative medicine

(CAM)

Compliance

Inflammatory bowel diseases (IBD)

\begin{abstract}
A B S T R A C T
Background: The use of complementary and alternative medicines is increasing among chronic patients, particularly those afflicted with inflammatory bowel diseases.

Aim: This study aimed to address the prevalence of complementary and alternative medicines use among Portuguese inflammatory bowel diseases' patients.

Methods: Patients were invited to fill an anonymous questionnaire concerning the use of complementary and alternative medicines.

Results: Thirty-one per cent of the patients reported having used complementary and alternative medicines in the past, whereas $12 \%$ were using them by the time the questionnaire was administered. Fifty-nine per cent of the users did not share this information with their physician, whereas $14 \%$ and $8 \%$ discontinued their medication and periodical examination, respectively. Steroids prescription $(\mathrm{OR}=2.880)$ and a higher instruction level $(\mathrm{OR}=3.669)$ were predictors of complementary and alternative medicines use in this cohort.

Conclusions: Roughly a third of Portuguese IBD patients had used CAM. Steroid treatment and an academic degree are associated with CAM use. Given the potential side effects and interactions, patient information about the benefits and limitations of conventional and complementary treatments should be reinforced. (c) 2017 Editrice Gastroenterologica Italiana S.r.l. Published by Elsevier Ltd. All rights reserved.
\end{abstract}

\footnotetext{
* Corresponding author.

E-mail address: fasportela@gmail.com (F. Portela).
}

\section{Introduction}

Inflammatory bowel diseases (IBD), which include Crohn's disease (CD) and ulcerative colitis (UC), are lifelong immune-mediated disorders characterized by a relapse and remitting course, and 
Conventional therapy use

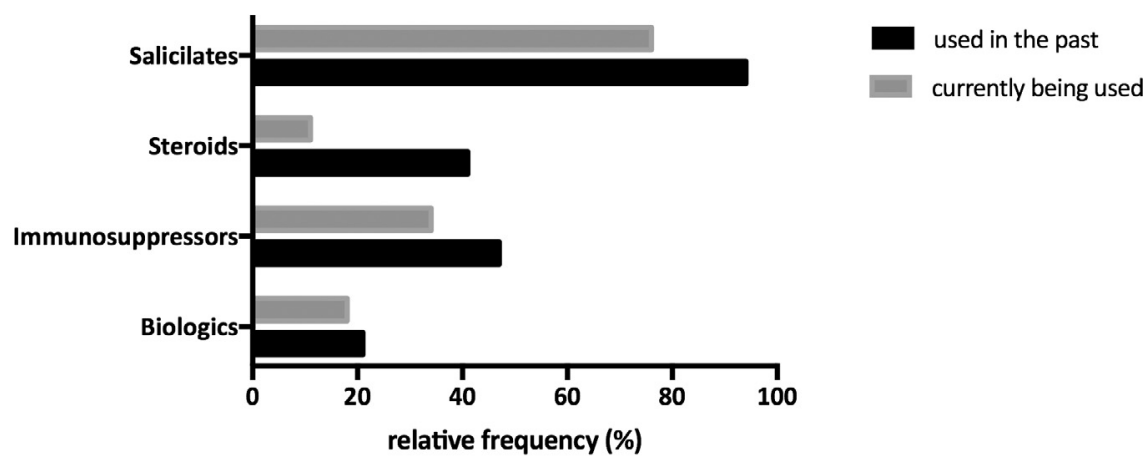

Fig 1. Relative frequency of conventional therapies used among the studied IBD population.

particularly common in developed countries [1,2]. Whereas UC is limited to the rectum and colon, CD can virtually affect any part of the gastrointestinal tract (GI), although being more commonly found along the ileum and in the beginning of the colon. Despite this and other differences, CD and UC share a characteristic heavy burden of symptomatology: rectal bleeding, abdominal pain, diarrhea and fatigue are some of the more conspicuous symptoms affecting IBD patients. So far, no curative therapies have been developed for $\mathrm{UC}$ or $\mathrm{CD}$, and therefore the current management of these diseases aims to control the symptoms and improve patients' health-related quality of life (HRQoL). This management relies on quite complex therapeutic lines that can include steroids, anti-inflammatory drugs (such as 5-aminosalicylic acid [5-ASA]), immunomodulators (such as azathioprine [AZA] or anti-tumour necrosis factor $\alpha$ [anti-TNF $\alpha]$ ), and bowel surgery. Understandably, both IBD and the medications taken to control the burden of symptoms have a high impact on patients' HRQoL and are associated with a higher prevalence of psychological disorders [3].

The awareness and interest in complementary and alternative medicines (CAM) has been raising among IBD patients. The European Crohn's and Colitis Organisation (ECCO) defines complementary and alternative therapies according to their pattern of use: complementary therapies are those that are used alongside with conventional medicine, whereas alternative therapies are those that are used in the place of conventional medicine $[1,2]$. The holistic and self-healing nature of CAM is particularly attractive to chronic patients, as it is the popular notion that CAM has no side effects. In the context of IBD, different techniques and products are commonly used, some of which have been the subject of laboratory tests and/or clinical trials: treatment with helminths [4], gut-directed hypnotherapy [5-8], herbal medicines [8-12], acupuncture [8,13], nutritional strategies [8,14,15], exercise [16], and antioxidant therapy [17] are a few of them. Some of the results obtained in these trials are indeed promising for instance, the association of gut-directed hypnotherapy with a reduced IBD-related inflammation and an increase of HRQoL [6], or the demonstration that Boswellia serrata gum resin and Plantago ovata seeds are as effective as 5-ASA in the treatment of UC [11]. However, these results need to be interpreted with caution, as the lack of high-quality data remains an issue in most CAM studies. The efficacy and safety of CAM need to be evaluated by multicentric and double blind randomized controlled trials with large samples before definitive conclusions are drawn.

The knowledge of CAM utilization patterns among a certain community is absolutely necessary in order to prevent interactions with conventional medicine, potential side effects and a decrease in therapeutic compliance. Although such an issue has been approached in several countries of North America, Europe and Asia, the picture in Portugal remains unknown, and the strong impact of regional and cultural factors in CAM utilization prevents the extrapolation of the results from other European countries. As so, this study aimed to explore the use and attitudes of Portuguese IBD patients toward CAM based on the results of an anonymous survey.

\section{Material and methods}

\subsection{Study population}

IBD patients were recruited from APDI (Portuguese IBD patients' association) and from 13 different university and community hospitals between October 2011 and March 2012. Patients older than 18 years and with a confirmed diagnosis of UC, CD or unclassified colitis were invited to participate in the study. These patients were given a questionnaire containing 31 yes or no and multiple choice questions focused on social-demographic aspects (gender, age, instruction level and professional sector), clinical data, compliance, and CAM use and attitudes. All questionnaires were anonymous and self-administered, being afterwards returned by mail. The local ethic committee has approved this study.

\subsection{Statistical analysis}

Categorical variables were described using absolute and relative frequencies, whereas continuous variables were described using average, median, standard deviation, percentiles, and minimum/maximum values. The Pearson Chi-square test was used to test the independence of categorical variables. $T$ and Mann-Whitney tests were used to test the similarity of groups, depending on whether their distribution was normal or not normal. Logistic regression was employed to determine which factors could independently predict the use of CAM. All tests were evaluated considering a significance level of $5 \%$. All data was arranged, processed and analysed with SPSS ${ }^{\circledR}$ v.19.0 data (Statistical Package for Social Sciences), whereas graphs were designed using Prism 7.

\section{Results}

\subsection{Cohort characterization}

A total of 750 questionnaires were distributed, and 442 were returned and considered valid, which corresponds to a response rate of $59 \%$. Nine questionnaires (1.2\%) were considered invalid due to a lack of answers. The socio-demographic and clinical characteristics of the study population are summarized in Table 1. Most respondents were female (57\%), were educated to a college degree 
Table 1

Cohort characterization.

\begin{tabular}{|c|c|c|}
\hline \multicolumn{3}{|l|}{ Gender (n, \%) } \\
\hline Male & 192 & 43 \\
\hline Female & 250 & 57 \\
\hline Age (average, sd) & 43 & 13 \\
\hline \multicolumn{3}{|l|}{ Instruction level (n, \%) } \\
\hline Mandatory & 126 & 27 \\
\hline High-school & 155 & 33 \\
\hline College & 182 & 39 \\
\hline \multicolumn{3}{|l|}{ Professional sector (n, \%) } \\
\hline Primary & 10 & 3 \\
\hline Secondary & 70 & 19 \\
\hline Tertiary & 298 & 79 \\
\hline \multicolumn{3}{|l|}{$\operatorname{IBD}(\mathrm{n}, \%)$} \\
\hline Ulcerative colitis & 154 & 33 \\
\hline Crohn's disease & 299 & 65 \\
\hline Unclassified & 8 & 2 \\
\hline Disease duration (median, P05-P95) & 11 & $3-30$ \\
\hline \multicolumn{3}{|c|}{ Hospital admissions (previous 5 years) (n, \%) } \\
\hline None & 253 & 56 \\
\hline 1 & 90 & 20 \\
\hline $2-5$ & 94 & 21 \\
\hline$>5$ & 13 & 3 \\
\hline \multicolumn{3}{|c|}{ Bowel-related surgeries (previous 5 years) } \\
\hline$(\mathrm{n}, \%)$ & 96 & 22 \\
\hline (median, P05-P95) & 1 & $(1-3)$ \\
\hline \multicolumn{3}{|l|}{ Conventional therapy prescription ( $\mathrm{n}, \%)$} \\
\hline Yes & 329 & 76 \\
\hline \multicolumn{3}{|l|}{ Disease-related current well-being ( $\mathrm{n}, \%$ ) } \\
\hline Ok & 182 & 40 \\
\hline So-so & 213 & 47 \\
\hline Not ok & 54 & 12 \\
\hline Very bad & 9 & 2 \\
\hline \multicolumn{3}{|c|}{ Have you ever used alternative medicines because of your IBD? (n, \%) } \\
\hline Yes & 145 & 31 \\
\hline \multicolumn{3}{|c|}{ Do you currently use alternative medicines because of your IBD? (n, \%) } \\
\hline Yes & 57 & 12 \\
\hline \multicolumn{3}{|c|}{ How did you feel regarding your disease by the time you decided to use alternative medicines? (n, \%) } \\
\hline Ok & 14 & 10 \\
\hline So-so & 36 & 25 \\
\hline Not ok & 49 & 34 \\
\hline Very bad & 47 & 32 \\
\hline
\end{tabular}

(39\%) and worked in the tertiary sector (79\%). UC afflicted 33\% of the respondents, whereas $65 \%$ of them had a CD diagnosis and $2 \%$ had unclassified colitis. The median time of disease duration was 11 years, and $22 \%$ of all patients had undergone at least one bowelrelated surgery in the previous five years. During the same time period, 20 and $21 \%$ of all patients had one or two to five hospital admissions, respectively. Conventional therapies were prescribed to a total of $76 \%$ of all respondents, and the distribution of those therapies is depicted on Fig. 1: salicylates were the most commonly prescribed medications (94\% of the respondents had used them in the past and $76 \%$ were using them by the time the questionnaire was administered), followed by immunosuppressors (47\% in the past and $34 \%$ by the time the questionnaire was administered). The prescription of steroids was relatively common in the five years preceding this study ( $41 \%$ of patients were on steroids), but by the time the questionnaire was administered only $11 \%$ of the responders were medicated with these drugs. Most patients (87\%) reported they were feeling at least partially well in relation to their IBD (Table 1).

A total of 145 patients (31\%) of this cohort had used some kind of CAM to treat their IBD in the past, and 57 (12\%) were still doing so by the time this questionnaire was distributed (Table 1 ). The majority of these patients (66\%) stated that they were either "not ok" or "very bad" in relation to their IBD by the time they decided to resort to CAM. The types of CAM used are depicted in Fig. 2, alongside with their relative frequencies. Herbal medicines and homeopathy were the CAM types more frequently used by the patients in the past $39 \%$ and $42 \%$, respectively), but only herbal medicines remained in the top preferences of the patients by the time the questionnaire was addressed (46\%), followed by vitamins intake (30\%). Homeopathy dropped down to a rate of utilization of $18 \%$.

\subsection{Attitudes and reasons leading to and following CAM utilization}

The inability of conventional medicine to improve their condition was the most commonly reported reason for patients to resort to CAM (33\%), and $72 \%$ did so after receiving advice from a colleague, friend of family member (Fig. 3). A total of 67\% of all CAM users reported a positive outcome of the experience (i.e., they felt "better" or "much better" after CAM use). The costs associated with CAM were considerably high, with $66 \%$ of the CAM users spending over $50 €$ per month in these medicines, and $41 \%$ reporting a monthly cost over $100 €$. Indeed, financial reasons were the second most cited reason for patients to abandon CAM after experiencing it (44\%), surpassed only by the absence of positive outcomes (51\%). In what concerns the potential effect of CAM use on conventional medicine compliance, $86 \%$ and $92 \%$ of the respondents reported to have maintained the conventional therapy and the periodical examinations and analyses (respectively) during the time period they were using CAM. Finally, 59\% of the CAM users concealed this information from their attending physician, and $71 \%$ did so because they were afraid of the physician reaction (Fig. 3). Still, $85 \%$ of all IBD patients would appreciate the opportunity to discuss CAM with their physician. 


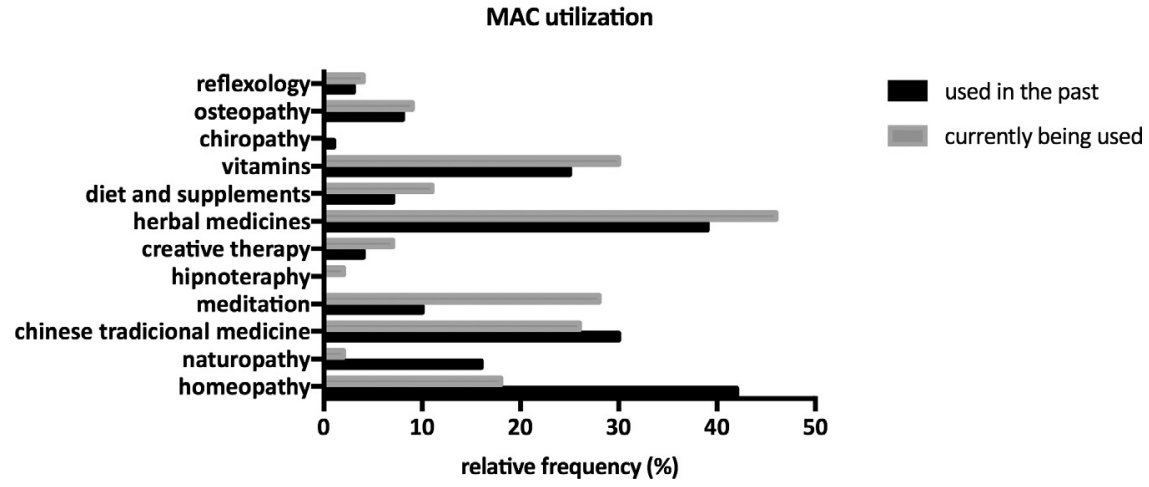

Fig. 2. Relative frequency of CAM therapies used among the CAM users.

Why have you decided to use alternative medicines?

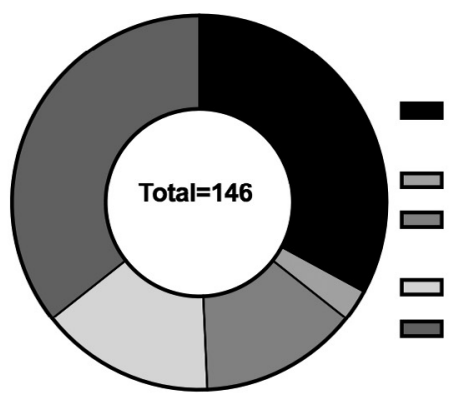

$32.88 \%$ I didn't feel better with the medication prescribed by my physician

$\square 2.74 \%$ I did not trust my physician

$13.70 \%$ Conventional therapy is not able to cure the disease

$15.07 \%$ Conventional therapies' side effects

$35.62 \%$ other reasons
Who suggested you to try alternative medicines?

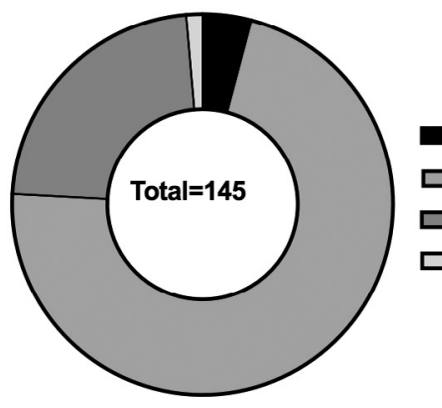

4.14\% My physician

$71.72 \%$ A friend, colleage or relative

$22.76 \%$ No one

$1.38 \%$ I searched through the web
How much have you spent/do you spend on alternative medicines monthly?

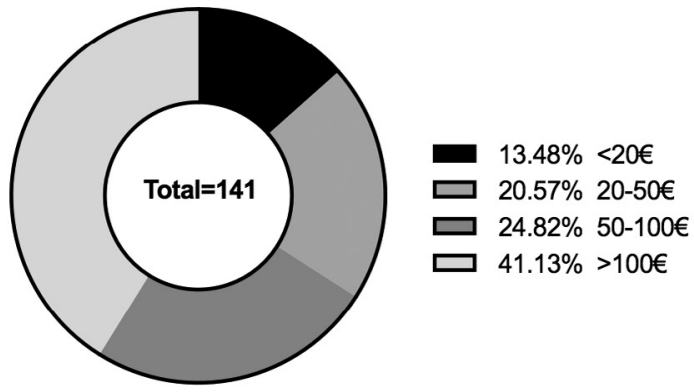

How have you felt after using alternatives medicine?

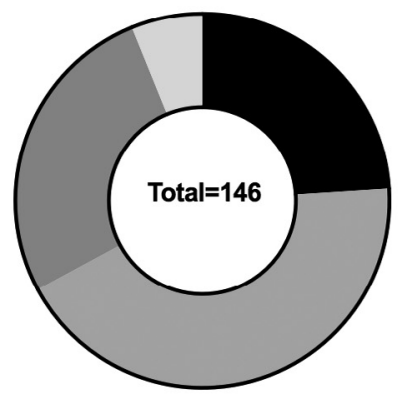

$23.97 \%$ much better

$\square 43.15 \%$ better

. $26.71 \%$ the same

6.16\% worst
If you are using/have used CAM without informing your physician, what was/is the reason for that?

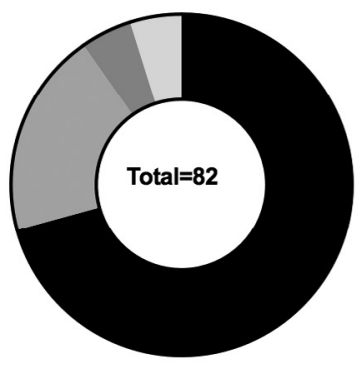

$70.73 \%$ I am/was afraid of the physician reaction

$19.51 \%$ I don't/didn't think he/she needs to know

$\square .88 \%$ I am/was ashamed of doing so

4.88\% I have/had abandoned medical consultations
If you have used alternative medicines but are not using them right now, what was the motive for abandoning it?

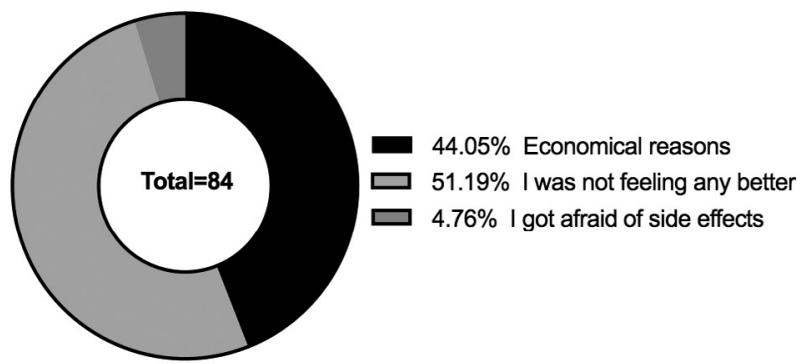

Fig. 3. Motivational factors and attitudes of CAM use. 
Table 2

Association between the use of CAM and other demographic or disease-related variables.

\begin{tabular}{|c|c|c|c|c|c|}
\hline & \multicolumn{4}{|c|}{ Have you ever used MAC? } & \multirow[t]{2}{*}{$\mathrm{p}^{*}$} \\
\hline & Yes & & No & & \\
\hline \multicolumn{5}{|l|}{ Gender (n, \%) } & 0.033 \\
\hline Male & 48 & $(36)$ & 140 & $(47)$ & \\
\hline Female & 87 & $(64)$ & 161 & (53) & \\
\hline Age (average, sd) & 40 & $(13)$ & 45 & $(14)$ & $<0.001^{* *}$ \\
\hline \multicolumn{5}{|l|}{ Instruction level (n, \%) } & $<0.001$ \\
\hline Mandatory & 20 & $(14)$ & 103 & $(33)$ & \\
\hline High-school & 48 & (33) & 106 & $(34)$ & \\
\hline College & 76 & $(53)$ & 104 & $(33)$ & \\
\hline \multicolumn{5}{|l|}{ Professional sector (n, \%) } & 0.063 \\
\hline Primary & 1 & (1) & 9 & $(4)$ & \\
\hline Secondary & 16 & (13) & 53 & $(21)$ & \\
\hline Tertiary & 102 & $(86)$ & 194 & $(76)$ & \\
\hline \multicolumn{5}{|l|}{$\operatorname{IBD}(\mathrm{n}, \%)$} & 0.416 \\
\hline Ulcerative colitis & 41 & $(29)$ & 109 & (35) & \\
\hline Crohn's disease & 99 & $(70)$ & 199 & (63) & \\
\hline Unclassified & 2 & (1) & 6 & $(2)$ & \\
\hline Disease duration (median, P05-P95) & $10(4-27)$ & & $11(3-30)$ & & $0.839^{* * *}$ \\
\hline \multicolumn{5}{|l|}{ Disease-related current well-being (n, \%) } & 0.837 \\
\hline $\mathrm{Ok}$ & 54 & $(39)$ & 126 & $(40)$ & \\
\hline So-so & 65 & $(46)$ & 144 & $(46)$ & \\
\hline Not ok & 17 & $(12)$ & 37 & $(12)$ & \\
\hline Very bad & 4 & $(3)$ & 5 & $(2)$ & \\
\hline \multicolumn{5}{|l|}{ Hospital admissions (previous 5 years) (n, \%) } & 0.098 \\
\hline None & 69 & $(50)$ & 180 & $(59)$ & \\
\hline 1 & 26 & (19) & 64 & $(21)$ & \\
\hline $2-5$ & 38 & $(28)$ & 55 & $(18)$ & \\
\hline$>5$ & 5 & $(4)$ & 7 & $(2)$ & \\
\hline \multicolumn{5}{|l|}{ Bowel-related surgeries (previous 5 years) } & 0.601 \\
\hline$(\mathrm{n}, \%)$ & 32 & $(24)$ & 63 & $(21)$ & \\
\hline (median, P05-P95) & 2 & $(1-4)$ & 1 & $(1-3)$ & $0.318^{* * *}$ \\
\hline \multicolumn{5}{|l|}{ Conventional therapy prescription (n, \%) } & 0.003 \\
\hline Yes & 117 & $(85)$ & 208 & $(71)$ & \\
\hline \multicolumn{6}{|l|}{ Conventional therapy during the last 5 years (n, \%) } \\
\hline Biologics & & & & & 0.088 \\
\hline Yes & 36 & $(26)$ & 57 & $(19)$ & \\
\hline \multicolumn{5}{|l|}{ Immunossupressors } & 0.024 \\
\hline Yes & 77 & $(55)$ & 133 & $(43)$ & \\
\hline \multicolumn{5}{|l|}{ Steroids } & 0.001 \\
\hline Yes & 73 & $(53)$ & 105 & $(36)$ & \\
\hline \multicolumn{5}{|l|}{ Salicilates } & 0.053 \\
\hline Yes & 113 & $(91)$ & 279 & $(96)$ & \\
\hline \multicolumn{6}{|l|}{ Current conventional therapy (n, \%) } \\
\hline Biologics & & & & & 0.043 \\
\hline Yes & 30 & $(23)$ & 45 & $(15)$ & \\
\hline Immunossupressors & & & & & 0.358 \\
\hline Yes & 48 & $(38)$ & 97 & $(33)$ & \\
\hline Steroids & & & & & 0.003 \\
\hline Yes & 23 & $(18)$ & 24 & $(8)$ & \\
\hline Salicilates & & & & & 0.078 \\
\hline Yes & 90 & $(70)$ & 231 & $(78)$ & \\
\hline
\end{tabular}

Note: Bold means significant $(\mathrm{p}<0,05)$.

* Pearson Chi-square.

** $T$ test for independent samples.

*** Mann-Whitney Test.

\subsection{The typical profile of a CAM user-associated variables and predictors}

Table 2 lists the socio-demographic and clinical variables investigated and their association with CAM use. Neither disease type nor disease duration nor number of hospital admissions and bowel surgeries are associated to CAM use in a significant fashion. On the other hand, patients who are younger (an average of 40 years old vs. $45, \mathrm{p}<0.001$ ), females ( $64 \%$ of all users, $\mathrm{p}=0.033$ ), and that have a college degree $(53 \%$ of all users, $\mathrm{p}<0.001$ ) are particularly prone to use CAM. Moreover, CAM use is more common among patients to whom conventional therapy was prescribed $(p=0.003)$, particularly those that were on immunosuppressors or steroids in the five years preceding the questionnaire administration $(p=0.024$ and $\mathrm{p}=0.001$, respectively), or on steroids or biologicals by the time the questionnaire was administered $(\mathrm{p}=0.003$ and $\mathrm{p}=0.043$, respectively).

A logistic regression was employed to discern which factors were predictive of CAM use (Table 3). Although there were a number of significant variables on the univariate model (gender, age, instruction level, hospital admissions in the previous five years and prescription of conventional therapy, namely immunosuppressors, steroids and biologicals), only two of them retained their significance in the multivariate model: instruction level and steroids use. IBD patients educated to a college degree were more than three times more likely to use CAM when compared to those with the mandatory level of instruction $(\mathrm{OR}=3.669,95 \% \mathrm{CI}$ : $1.554,8.664)$, whereas those that had used steroids at some time in the five years preceding the administration of the questionnaire were almost 
Table 3

Multivariate analysis of variables associated with CAM use.

\begin{tabular}{|c|c|c|c|c|c|c|}
\hline & \multicolumn{3}{|c|}{ Univariate model ${ }^{\mathrm{a}}$} & \multicolumn{3}{|c|}{ Multivariate model ${ }^{\mathrm{b}}$} \\
\hline & OR & CI95\% & $\mathrm{p}$ & OR & CI95\% & $\mathrm{p}$ \\
\hline \multicolumn{7}{|l|}{ Gender } \\
\hline Male & Ref & & & & & \\
\hline Female & 1.576 & $1.037-2.396$ & 0.033 & & & \\
\hline Age, average (stdev) & 0.972 & $0.957-0.988$ & $<0.001$ & & & \\
\hline \multicolumn{7}{|l|}{ Instruction level } \\
\hline Mandatory & Ref & & & Ref & & \\
\hline High-school & 2.332 & $1.295-4.198$ & 0.005 & 2.255 & $0.900-5.650$ & 0.083 \\
\hline College & 3.763 & 2.144-6.608 & $<0.001$ & 3.669 & $1.554-8.664$ & 0.003 \\
\hline \multicolumn{7}{|l|}{ Professional sector } \\
\hline Primary & Ref & & & & & \\
\hline Secondary & 2.717 & $0.320-23.100$ & 0.360 & & & \\
\hline Tertiary & 4.732 & $0.591-37.871$ & 0.143 & & & \\
\hline \multicolumn{7}{|l|}{ IBD } \\
\hline Unclassified colitis & Ref & & & & & \\
\hline Ulcerative colitis & 1.128 & $0.219-5.818$ & 0.885 & & & \\
\hline Crohn's disease & 1.492 & $0.296-7.529$ & 0.628 & & & \\
\hline Disease duration & 0.996 & $0.971-1.020$ & 0.721 & & & \\
\hline \multicolumn{7}{|c|}{ Disease-related current well-being } \\
\hline Ok & Ref & & & & & \\
\hline So-so & 1.053 & $0.683-1.624$ & 0.814 & & & \\
\hline Not ok & 1.072 & $0.556-2.068$ & 0.835 & & & \\
\hline Very bad & 1.867 & $0.483-7.221$ & 0.336 & & & \\
\hline \multicolumn{7}{|c|}{ Hospital admissions (previous 5 years) } \\
\hline None & Ref & & & & & \\
\hline 1 & 1.060 & $0.622-1.807$ & 0.831 & & & \\
\hline $2-5$ & 1.802 & $1.095-2.966$ & 0.020 & & & \\
\hline$>5$ & 1.863 & $0.572-6.068$ & 0.302 & & & \\
\hline \multicolumn{7}{|c|}{ Bowel-related surgeries (previous 5 years) } \\
\hline Yes & 1.138 & $0.701-1.847$ & 0.601 & & & \\
\hline No & Ref & & & & & \\
\hline How many surgeries? & 1.219 & $0.779-1.908$ & 0.386 & & & \\
\hline \multicolumn{7}{|c|}{ Conventional therapy prescription } \\
\hline Yes & 0.450 & $0.265-0.764$ & 0.003 & & & \\
\hline No & Ref & & & & & \\
\hline \multicolumn{7}{|c|}{ Conventional therapy during the last 5 years } \\
\hline \multicolumn{7}{|c|}{ Biologics } \\
\hline Yes & 1.510 & $0.9 .9-2.429$ & 0.089 & & & \\
\hline No & Ref & & & & & \\
\hline \multicolumn{7}{|l|}{ Immunosuppressors } \\
\hline Yes & 1.583 & $1.060-2.364$ & 0.025 & & & \\
\hline No & Ref & & & & & \\
\hline \multicolumn{7}{|l|}{ Steroids } \\
\hline Yes & 2.011 & 1.333-3.032 & 0.001 & 2.880 & 1.619-5.124 & $<0.001$ \\
\hline No & Ref & & & Ref & & \\
\hline \multicolumn{7}{|l|}{ Salicilates } \\
\hline Yes & 0.442 & $0.189-1.030$ & 0.059 & & & \\
\hline No & Ref & & & & & \\
\hline Current conventional thera & & & & & & \\
\hline Biologics & & & & & & \\
\hline Yes & 1.701 & 1.013-2.854 & 0.044 & & & \\
\hline No & Ref & & & & & \\
\hline Immunosuppressors & & & & & & \\
\hline Yes & 1.225 & $0.795-1.887$ & 0.358 & & & \\
\hline No & Ref & & & & & \\
\hline Steroids & & & & & & \\
\hline Yes & 2.473 & $1.338-4.574$ & 0.004 & & & \\
\hline No & Ref & & & & & \\
\hline Salicilates & & & & & & \\
\hline Yes & 0.656 & $0.410-1.049$ & 0.079 & & & \\
\hline No & Ref & & & & & \\
\hline
\end{tabular}

Note: Bold means significant ( $\mathrm{p}<0,05)$.

a Dependent variable: MAC use.

b Dependent variable: MAC use; independent variables: all of those that had a p value below 0.20 in the univariated model selected by the Forward method.

three times more likely to use CAM than those who had not taken any steroids in that time period $(\mathrm{OR}=2.880,95 \% \mathrm{CI}: 1.619,5.124)$.

\section{Discussion}

The utilization of CAM seems to be rising among chronic patients, particularly among those that suffer from IBD. But despite the common perception that CAM is safe, some of the products employed may have kidney and liver toxicity, and/or may interact with conventional therapeutics, decreasing their effect. The knowledge on the patterns of CAM use is fundamental to tackle the issues mentioned above. Such information was, to the best of our knowledge, unavailable in what concerns Portuguese IBD patients. This 
study aimed to assess CAM use and its underlying reasons and attitudes in these patients.

The comparison of the prevalence of CAM use among different countries or regions is often made difficult by a series of cultural and methodological issues. First of all, the definition of what fits the CAM concept varies: products and practices such as probiotics, exercise, relaxation, vitamin supplementation and prayer are considered to be CAM in a few studies but not in others. Understandably, the CAM prevalence tends to be higher in the studies that pre-define a larger set of therapies as CAM. On the other hand, many studies do not specify whether patients used CAM specifically to improve their IBD - some IBD patients may have used CAM for other reasons, such as psychological stress or to promote general well-being. Finally, a number of studies do not clarify whether their prevalence values refer to "ever used" or "current use" of CAM. Still, the CAM utilization among Portuguese IBD patients seems to be similar to that found across other South European countries $(23.6 \%-28.2 \%$ in Italy $[18,19]$ and $23.1 \%$ in Spain [20]), Korea (29.5\%-30\% [21,22]), UK (26\% [23]) and Hungary (30.9-31.7\% [24]). On the other hand, the prevalence of CAM use seems to be higher among IBD patients from Germany (51.3\%-52\% [25,26]), France (65.6\% [27]), Norway (30-49\% [28,29]), Canada (21\%-56\% [30,31]), Australia (45.4\% [32]) and New Zealand (44.1\% [33]). Our results are based on a $59 \%$ response rate which is less than what was achieved in some papers $[18,28]$ but similar to others [25]. The fact that patients were free to answer the questionnaires at home and returned them by mail may have had a negative impact on the response rate but, in our opinion, it was important to limit the constraints inherent to hospital environment.

Regarding the outcomes of CAM use, $67 \%$ of the respondents in this study reported feeling "better" or "much better". This value is higher than that found among other studies that addressed this parameter, which varied between $26 \%$ and $55.6 \%$ [20,21,23]. D'Inca et al. has further analysed the specific reasons that underlie the patients' satisfaction with CAM, and observed that whether $45.5 \%$ of CAM users reported a general sense of well-being but without clinical effect, $39.7 \%$ and $21.8 \%$ actually experienced an improvement in their IBD symptoms and a reduction in the number of flares, respectively [18]. It is important to notice that the positive effects of CAM in this and other studies are self-reported, and are therefore the result of a complex interaction between physical and psychological factors, where the placebo effect cannot be dismissed.

The preferences in terms of CAM type unveiled an interesting pattern: whereas homeopathy, herbal medicine and Chinese traditional medicine appear to have been popular in the time period that preceded the questionnaire administration, herbal medicine, vitamins, meditation and traditional Chinese medicine were the preferred therapies by the time the patients entered the study. These results are not uncommon: homeopathy and/or herbal medicines tend to rank high among the preferences of European CAM users [18-20,23-26,29,34]. On the other hand, probiotics tend to be the preferred CAM in North America [30,31]. Once again, these differences may result from a simple methodological bias: with a few exceptions, probiotics are not considered to be CAM among European studies (and therefore are not an option on the questionnaires).

The absence of improvement following conventional therapy was the most cited reason for CAM users to try these therapies (33\%), followed by the possible side effects of conventional therapies (15\%) and by the inability of conventional medicine to cure their disease (14\%). This motivational context is similar to that observed in other studies in what concerns the so-called push-factors (i.e., factors that push a patient away from conventional medicine) [19,26,30-32,34]. Unfortunately, we have failed to include in our questionnaire the pull-factors (i.e., factors that pull a patient toward CAM), such as the possibility to have a greater con- trol over the disease and/or an active involvement in the treatment, and the will to undertake a holistic and a more "natural" therapeutic approach $[26,30-32,34]$. These factors are likely relevant in the studied population, as $36 \%$ of the respondents chose "other reasons" when asked about their motives to try CAM and facing only push-factors as options.

The possible impact of CAM use on the adherence to conventional medicine is an important issue: concerning the population assessed in this study, $14 \%$ and $8 \%$ of the CAM users discontinued medication and periodic examinations (respectively) during the time period they were on CAM. These proportions are similar to those found in other studies [18,20,22]. Not only are these values worrisome by themselves, but they can also conceal a darker reality. In fact, one should keep in mind that this compliance is self-reported. And if, on one hand, patients are not always willing to admit they discontinued their medication, on the other hand, the lack of adherence may actually be unintended (and unnoticed by patients). Indeed, Nguyen et al. have shown that CAM use was associated with a less favorable adherence to conventional therapy, but $97 \%$ of non-adherents reported that their attitude was unintentional [31]. Conversely, Weizman et al. concluded that CAM use was not associated with a lack of adherence to conventional therapies [30]. More studies are needed to clarify this issue and to develop compliance-enhancing strategies for IBD patients, both CAM users and non-users.

Doctor-patient communication and mutual trust is an unavoidable key aspect one has to consider when addressing CAM use. In this study, $59 \%$ of CAM users did not disclose the fact that they were using CAM to their physician, and $71 \%$ of them claimed they did so because they were afraid of the MD reaction. However, $85 \%$ of all IBD patients in this cohort would appreciate the possibility to discuss CAM with their attending physician. This scenario is transversal to different IBD populations: a considerable proportion of CAM users choose not to disclose that information to their physician $[25,30,32]$. A qualitative study by Lindberg et al. suggested that IBD patients would like to discuss CAM use with their physician, but they do not initiate any conversation on this subject for fear they would not be taken seriously [35]. In contrast, gastroenterologists were shown to have a generally positive attitude regarding CAM: a study from Gallinger and Nguyen based on a web survey reported that $68 \%$ of gastroenterologists believed that CAM could be a good adjuvant in IBD therapy and $72 \%$ felt comfortable discussing it [36]; a qualitative study by Lindberg et al. reported that health professionals believed CAM belonged within healthcare and was relevant to conventional therapeutics [37]. Notwithstanding, a common complaint among all gastroenterologists and other health professionals was the lack of formal knowledge in the area. Given the increasing importance and prevalence of CAM use, the introduction of CAM-related topics in medical schools and workshops of continuing medical education is absolutely necessary, and will undoubtedly be a key step to facilitate doctor-patient communication in this particular subject.

The female gender, younger age, college education, previous use of immunosuppressors and steroids, and current use of biologicals and steroids were significantly associated with CAM use. College instruction and previous use of steroids were actually independent predictor factors of CAM use, with ORs of 3.669 and 2.880 , respectively. These relationships have been noticed before in several studies and, opposite to what happens with other CAM use features, seem to be transversal across different geographic locations and IBD populations [18,19,22,24,26,28-30,32,33]. Other factors associated with CAM use have been depicted in other studies, but those were either not explored or failed to be associated with CAM use in the present study: evidence for a health-conscious lifestyle, number of hospital admissions and consultations, drug-side effects and other complications, relapses, long-term evo- 
lution of the disease, need for psychological support, presence of extra-intestinal manifestations, permanent employment, higher income and presence of co-morbidities [18-20,22,26,28,32,33,38].

Conventional therapies have known side effects, the fear of which may lead patients to resort to CAM in the search of what they believe to be a more natural and less toxic approach. The fact that previous use of steroids was found as an independent predictor of CAM use can be, at least in part, explained by the side effects profile of these drugs. Steroids can also be considered a surrogate mark of a moderate or severe disease, which has been linked to CAM use in other studies [18,19,22,29]. On the other hand, the association of CAM use to a high level of instruction is quite common and may be related to the fact that college-educated patients are more resourceful and more likely to explore their IBD disease from different perspectives. Moreover, the use of CAM gives them a sense of control over their disease. Additionally, they are also more likely to be able to afford CAM: in fact, and as shown by this and other studies, CAM use is rather expensive $[18,27]$. The association of CAM use with permanent employment and higher income seen in other studies supports this hypothesis [22,32,33]. Still, the relationship between college education and the use of therapies mostly deprived of scientific support merits further studies.

This study was based on an anonymous questionnaire that was distributed across the entire country (rural and urban areas) and included patients in different stages and with different severity of the diseases (patients were recruited not only from medical consultations but also from the Portuguese association of IBD patients). It has, however, a few limitations that should be noticed. One of them is inherent to all questionnaire-based CAM assessments - the lack of consistency between the questionnaires administered in different countries makes their comparisons difficult or even impossible. The development and national-validation of an international CAM questionnaire with a precise definition of what should be considered CAM [39], as well as the throughout characterization of the population enrolled, are key steps to solve these issues. Another limitation refers to the fact that the studied patients were in part recruited from conventional medicine care centers: satisfied users of CAM are unlikely to attend these centers, which introduces a bias in the sampling process. The disease status and CAM improvements were self-reported and not objectively evaluated - this is an unavoidable consequence of keeping the questionnaires anonymous; however, it does prevent one to identify placebo effects and inflammatory bowel syndrome-related worsening of symptoms. Finally, the questionnaire was not previously validated, it did not explore positive motivational factors, and we had no information on the patients' psychological state of mind and HRQoL.

As a global conclusion, the CAM use patterns of IBD patients in Portugal match those previously found among other European countries: the typical user is a young female with a college education and an history of steroids prescription, whereas the preferred CAM type is herbalism. The prevalence is rather high and is intrinsically linked with the perceived inability of the conventional medicine to produce positive outcomes. Patient-doctor communication is an issue: patients would like to discuss CAM with their physicians, but they fear their reaction and end up not disclosing CAM use. Medicine faculties and continuing medical education should invest in disseminating formal knowledge on CAM, and physicians should improve their empathy and understand the benefits of an integrative healthcare, including conventional and non-conventional therapies. This would likely enhance patients' compliance and solve possible CAM-related adherence issues.

\section{Conflict of interest}

F. Portela received a presenting fee from: AbbVie, Ferring, MSD, Vifor Pharma. F Magro received a presenting fee from: AbbVie, Fer- ring, Falk, Hospira, PharmaKern, MSD, Schering, Lab. Vitoria, Vifor, OmPharma. All others authors: none to declare.

\section{Support}

GEDII (Portuguese IBD Study Group).

\section{Acknowledgments}

The authors would like to express their gratitude to Abbvie for supporting mail-related expenses, to Sandra Dias for her support as the coordinator of the national IBD group (GEDII - Grupo de Estudo de Doenças Inflamatórias Intestinais), and to Catarina L. Santos for medical writing assistance.

\section{References}

[1] Dignass A, Eliakim R, Magro F, et al. Second European evidence-based consensus on the diagnosis and management of ulcerative colitis part 1: definitions and diagnosis. Journal of Crohn's \& Colitis 2012;6:965-90.

[2] Van Assche G, Dignass A, Panes J, et al. The second European evidence-based consensus on the diagnosis and management of Crohn's disease: definitions and diagnosis. Journal of Crohn's \& Colitis 2010;4:7-27.

[3] Alarhayem A, Achebe E, Logue AJ. Psychosocial support of the inflammatory bowel disease patient. The Surgical Clinics of North America 2015;95:1281-93, vii-viii.

[4] Szkudlapski D, Labuzek K, Pokora Z, et al. The emering role of helminths in treatment of the inflammatory bowel disorders. Journal of Physiology and Pharmacology 2014;65:741-51.

[5] Moser G. The role of hypnotherapy for the treatment of inflammatory bowel diseases. Expert Review of Gastroenterology \& Hepatology 2014;8:601-6.

[6] Szigethy E. Hypnotherapy for inflammatory bowel disease across the lifespan. The American Journal of Clinical Hypnosis 2015;58:81-99.

[7] Peters SL, Muir JG, Gibson PR. Review article: gut-directed hypnotherapy in the management of irritable bowel syndrome and inflammatory bowel disease. Alimentary Pharmacology \& Therapeutics 2015;41:1104-15.

[8] Joos S. Review on efficacy and health services research studies of complementary and alternative medicine in inflammatory bowel disease. Chinese Journal of Integrative Medicine 2011;17:403-9.

[9] Salaga M, Zatorski H, Sobczak M, Chen C, Fichna J. Chinese herbal medicines in the treatment of IBD and colorectal cancer: a review. Current Treatment Options in Oncology 2014;15:405-20.

[10] Algieri F, Rodriguez-Nogales A, Rodriguez-Cabezas ME, Risco S, Ocete MA, Galvez J. Botanical drugs as an emerging strategy in inflammatory bowel disease: a review. Mediators of Inflammation 2015;2015:179616.

[11] Triantafyllidi A, Xanthos T, Papalois A, Triantafillidis JK. Herbal and plant therapy in patients with inflammatory bowel disease. Annals of Gastroenterology 2015;28:210-20.

[12] Gilardi D, Fiorino G, Genua M, Allocca M, Danese S. Complementary and alternative medicine in inflammatory bowel diseases: what is the future in the field of herbal medicine? Expert Review of Gastroenterology \& Hepatology 2014;8:835-46.

[13] Ji J, Lu Y, Liu H, et al. Acupuncture and moxibustion for inflammatory bowel diseases: a systematic review and meta-analysis of randomized controlled trials. Evidence-Based Complementary and Alternative Medicine 2013;2013:158352.

[14] Clarke JO, Mullin GE. A review of complementary and alternative approaches to immunomodulation. Nutrition in Clinical Practice 2008;23:49-62.

[15] Nguyen DL, Limketkai B, Medici V, Saire Mendoza M, Palmer L, Bechtold M. Nutritional strategies in the management of adult patients with inflammatory bowel disease: dietary considerations from active disease to disease remission. Current Gastroenterology Reports 2016;18:55.

[16] Bilski J, Mazur-Bialy A, Brzozowski B, et al. Can exercise affect the course of inflammatory bowel disease? Experimental and clinical evidence. Pharmacological Reports 2016;68:827-36.

[17] Moura FA, de Andrade KQ dos Santos JC, Araujo OR, Goulart MO. Antioxidant therapy for treatment of inflammatory bowel disease: does it work. Redox Biology 2015;6:617-39.

[18] D'Inca R, Garribba AT, Vettorato MG, et al. Use of alternative and complementary therapies by inflammatory bowel disease patients in an Italian tertiary referral centre. Digestive and Liver Disease 2007;39:524-9.

[19] Bertomoro P, Renna S, Cottone M, et al. Regional variations in the use of complementary and alternative medicines (CAM) for inflammatory bowel disease patients in Italy: an IG-IBD study. Journal of Crohn's \& Colitis 2010;4:291-300.

[20] Fernandez A, Barreiro-de Acosta M, Vallejo N, et al. Complementary and alternative medicine in inflammatory bowel disease patients: frequency and risk factors. Digestive and Liver Disease 2012;44:904-8.

[21] Kim SB, Park SJ, Chung SH, et al. Vaccination and complementary and alternative medicine in patients with inflammatory bowel disease. Intestinal Research $2014 ; 12: 124-30$ 
[22] Park DI, Cha JM, Kim HS, et al. Predictive factors of complementary and alternative medicine use for patients with inflammatory bowel disease in Korea. Complementary Therapies in Medicine 2014;22:87-93.

[23] Langmead L, Chitnis M, Rampton DS. Use of complementary therapies by patients with IBD may indicate psychosocial distress. Inflammatory Bowel Diseases 2002;8:174-9.

[24] Lakatos PL, Czegledi Z, David G, et al. Association of adherence to therapy and complementary and alternative medicine use with demographic factors and disease phenotype in patients with inflammatory bowel disease. Journal of Crohn's \& Colitis 2010;4:283-90.

[25] Joos S, Rosemann T, Szecsenyi J, Hahn EG, Willich SN, Brinkhaus B. Use of complementary and alternative medicine in Germany-a survey of patients with inflammatory bowel disease. BMC Complementary and Alternative Medicine 2006;6:19.

[26] Langhorst J, Anthonisen IB, Steder-Neukamm U, et al. Amount of systemic steroid medication is a strong predictor for the use of complementary and alternative medicine in patients with inflammatory bowel disease: results from a German national survey. Inflammatory Bowel Diseases 2005;11:287-95.

[27] Abitbol V, Lahmek P, Buisson A, et al. Impact of complementary and alternative medicine on the quality of life in inflammatory bowel disease: results from a French national survey. European Journal of Gastroenterology \& Hepatology 2014;26:288-94.

[28] Opheim R, Bernklev T, Fagermoen MS, Cvancarova M, Moum B. Use of complementary and alternative medicine in patients with inflammatory bowel disease: results of a cross-sectional study in Norway. Scandinavian Journal of Gastroenterology 2012;47:1436-47.

[29] Opheim R, Hoivik ML, Solberg IC, Moum B, Group IS. Complementary and alternative medicine in patients with inflammatory bowel disease: the results of a population-based inception cohort study (IBSEN). Journal of Crohn's \& Colitis 2012;6:345-53.

[30] Weizman AV, Ahn E, Thanabalan R, et al. Characterisation of complementary and alternative medicine use and its impact on medication adherence in inflammatory bowel disease. Alimentary Pharmacology \& Therapeutics 2012;35:342-9.
[31] Nguyen GC, Croitoru K, Silverberg MS, Steinhart AH, Weizman AV, Use of complementary and alternative medicine for inflammatory bowel disease is associated with worse adherence to conventional therapy: the COMPLIANT Study. Inflammatory Bowel Diseases 2016;22:1412-7.

[32] Mountifield R, Andrews JM, Mikocka-Walus A, Bampton P. Doctor communication quality and friends' attitudes influence complementary medicine use in inflammatory bowel disease. World Journal of Gastroenterology 2015;21:3663-70.

[33] Koning M, Ailabouni R, Gearry RB, Frampton CM, Barclay ML. Use and predictors of oral complementary and alternative medicine by patients with inflammatory bowel disease: a population-based, case-control study. Inflammatory Bowel Diseases 2013;19:767-78.

[34] Hilsden RJ, Verhoef MJ, Rasmussen H, Porcino A, DeBruyn JC. Use of complementary and alternative medicine by patients with inflammatory bowel disease. Inflammatory Bowel Diseases 2011;17:655-62.

[35] Lindberg A, Fossum B, Karlen P, Oxelmark L. Experiences of complementary and alternative medicine in patients with inflammatory bowel disease-a qualitative study. BMC Complementary and Alternative Medicine 2014;14:407.

[36] Gallinger ZR, Nguyen GC. Practices and attitudes toward complementary and alternative medicine in inflammatory bowel disease: a survey of gastroenterologists. Journal of Complementary \& Integrative Medicine 2014;11:297-303.

[37] Lindberg A, Ebbeskog B, Karlen P, Oxelmark L. Inflammatory bowel disease professionals' attitudes to and experiences of complementary and alternative medicine. BMC Complementary and Alternative Medicine 2013;13:349.

[38] Sirois FM. Health-related self-perceptions over time and provider-based complementary and alternative medicine (CAM) use in people with inflammatory bowel disease or arthritis. Complementary Therapies in Medicine 2014;22:701-9.

[39] Quandt SA, Verhoef MJ, Arcury TA, et al. Development of an international questionnaire to measure use of complementary and alternative medicine (ICAM-Q). Journal of Alternative and Complementary Medicine 2009;15:331-9. 